\title{
RARE CASE OF CHORIOANGIOMA OF PLACENTA.
}

Manisha M. Laddad, Sanjay Patil, Rajshree Bhosale, Yashodeep Sonawane

1. Assistant Professor. Department of Obstetrics \& Gynecology, Krishna Institute of Medical Sciences, Karad

2. Associate Professor. Department of Obstetrics \& Gynecology, Krishna Institute of Medical Sciences, Karad

3. Resident. Department of Obstetrics \& Gynecology, Krishna Institute of Medical Sciences, Karad

4. Resident. Department of Obstetrics \& Gynecology, Krishna Institute of Medical Sciences, Karad

\section{CORRESPONDING AUTHOR:}

Dr. Manisha M. Laddad,

75/A block, Vithal housing Society,

Malkapur, Karad (Dist. Satara)

Maharashtra 415110,

E-mail: drmanishald@gmail.com

ABSTRACT- Chorioangioma is a benign angioma of placenta arising from chorionic tissue. large chorioangioma has unfavorable effects on both mother and fetus. We had a rare case of large chorioangioma with uneventful pregnancy and labour and no adverse effects on both mother and fetus.

KEYWORDS: placenta, chorioangioma

CASE: A 23 yrs patient got admitted in KIMS on 10/10/2010 with H/O 8 months of amenorrhea and $\mathrm{C} / 0$ pain in abdomen since morning. She was primigravida with gestational age of 34.2 weeks. She had no major medical illness or surgery in past.

On general examination vitals were stable. On her abdomen examination, uterus was 34 weeks size with cephalic presentation and FHS - 140/ min. Per vaginally - Cx 2 c.m. dilated, 25 $\%$ effaced, bag of membranes present.

So, diagnosis was made - G1 with 34.2 weeks pregnancy with early preterm labour.

Patient had spontaneous, vaginal delivery at 5.30 am on $11 / 10 / 2010$ with no intrapartum or postpartum complications. Female baby - wt. $1.921 \mathrm{~kg}, 2$ loops of cord around neck, no anomalies, and maturity- 34 weeks. Baby shifted to NICU for detailed evaluation. By god grace, baby was fine \& had no congenital abnormality.

Placenta with two large masses sent for histopathological examination.

ULTRASONOGRAPHY: Single live intrauterine fetus of avg. gestational age 30-31 weeks, moderate polyhydramnios, fetal wt. $1460 \mathrm{Gms}$, no gross cong. anomalies. Placenta - fundal, An oval, iso to hypo echoic lesion in placental parenchyma along right lateral margin showing mild to moderate vascularity, m. 74x65 x $63 \mathrm{~mm}$. Another smaller, hypoechoic lesion m. $20 \mathrm{x}$ $17 \mathrm{~mm}$ is seen along Lt. Lateral margin of placenta.

E/o 2 placental mass lesion - likely to be Chorioangioma.

HISTOPATHOLOGY REPORT: Gross - Placenta totally m. 18x16x2.8 c.m. \& wt. 580 Gms. With central insertion of cord m. 20 c.m. in length. C/S of placenta showed few pale areas. Attached multiple masses on maternal surface near margin, largest $\mathrm{m} .8 \times 7 \times 3$ c.m. \& smallest $\mathrm{m} .2 \times 1 \times 1$ c.m. C/S of which is tan and brown. Fetal surface showed a small nodular mass bulging, m. 2 x1c.m. C/S was tan \& brown. 
DISCUSSION : DEFINITION:- A chorioangioma is a benign tumor of the placenta consisting of blood vessels and stroma that proliferates beyond normally developing chorionic villi.

INCIDENCE:-This is the most common primary tumor of the placenta, followed by hydatidiform mole and choriocarcinoma. Overall accepted incidence in the literature is 1 in 100 births.

PATHOGENESIS: A chorioangioma originates from primitive chorionic mesenchyme.

Three types: Less differentiated or more immature with a compact structure of mostly cellular elements. The second type is the mature angiomatous or vascular type. This is the most common type of chorioangioma composed of numerous small blood vessels and capillaries. The last type is characterized by degenerative changes.

Chorioangiomas vary in size from a few millimeters to several centimeters in diameter. These tumors are usually a single mass, but they can present as multiple separate masses. They are surrounded by a capsule or pseudocapsule. They are usually located on the fetal surface of the placenta and less often they can be located in the membranes and attached to the placenta by a vascular pedicle. Chorioangiomas have also been described on the umbilical cord.

ULTRASOUND DIAGNOSIS: Chorioangioma is usually depicted as a well circumscribed intraplacental mass with a complex echo pattern. Uniform and non-uniform echogenic appearances and multisystem masses have also been representative of this tumor. The echo density of the well delineated tumor differs from that of the placenta, allowing for its prompt recognition.

DIFFERENTIAL DIAGNOSIS: Angiomatous lesions should be differentiated from organizing blood clots and sub mucous myomas. The echo pattern of a blood clot tends to change over time, while the chorioangioma tends to remain unchanged. Myomas are usually located near the maternal surface of the placenta, while most large chorioangiomas are found on the fetal surface of the placenta. Partial hydatidiform moles are characterized by localized swelling of chorionic villi with focal trophoblastic hyperplasia and, on ultrasound, appear as multiple diffuse sonoluscent intraplacental areas.

\section{Associated functional and structural abnormalities}

\begin{tabular}{|l|}
\hline \multicolumn{1}{|c|}{ Placental } \\
\hline Circumvallate placenta \\
\hline Velamentous insertion of cord \\
\hline Placenta previa \\
\hline Abruptio placenta \\
\hline Fetal \\
\hline Anemia \\
\hline Cardiomegaly \\
\hline Sinusoidal heart rate pattern \\
\hline
\end{tabular}




\begin{tabular}{|l|}
\hline Edema \\
\hline Hydrops \\
\hline Demise \\
\hline Growth retardation \\
\hline Hepatomegaly \\
\hline Thrombocytopenia \\
\hline Disseminated intravascular coagulation \\
\hline Feto-maternal hemorrhage \\
\hline Microangiopathic hemolytic anemia \\
\hline Single umbilical artery \\
\hline Skin hemangioma \\
\hline Chromosomal anomalies \\
Trisomy 21 \\
\hline Translocation (2q:15q) \\
4 p monosomy \\
\hline Various congenital anomalies \\
\hline Maternal \\
\hline Hydramnios \\
\hline Preterm labor \\
\hline Premature rupture of membranes \\
\hline Preterm delivery \\
\hline Preeclampsia \\
\hline Antepartum hemorrhage \\
\hline Obstructed labor \\
\hline Theca lutein cyst \\
\hline Elevated serum a-fetoprotein \\
\hline
\end{tabular}

MANAGEMENT: Outcome is dependent on the size of the tumor. Smaller tumors have been found to be inconsequential. Large and diffuse tumors have been associated with pregnancy complications and therefore merit closer surveillance. Serial sonograms should be performed to assess the growth of the tumor, growth of the fetus, and development of hydrops. During the third trimester, fetal well-being should be monitored with fetal movement counts, heart rate monitoring and biophysical profiles. Doppler ultrasound \& fetal karyotyping will be useful. 


\section{REFERENCES:}

1. Sepulveda W, Alcalde JL, Schnapp C et-al. Perinatal outcome after prenatal diagnosis of placental chorioangioma . Obstetric Gynecol.

2. Zanardini C, Papageorghiou A, Bhide A et-al. Giant placental chorioangioma, natural history and pregnancy outcome . Ultrasound Obstetric Gynecol.

3. Shih JC, Ko TL, Lin MC et-al . Quantitative three-dimensional power Doppler ultrasound predicts the outcome of placental chorioangioma. Ultrasound Obstet Gynaecol

4. Fournet P, Eloit S, Allessandri JL et-al. [Chorioangioma of the placenta. Echographic, radiologic and anatomo-pathologic correlations] J Gynecol Obstet Biol Reprod (Paris). 1989;18 (7): 913-8. -

5. Hadi HA, Finley J, Strickland D. Placental chorioangioma: prenatal diagnosis and clinical significance. Am J Perinatol. 1993;10 (2): 14

6. Amer HZ, Heller DS. Chorangioma and related vascular lesions of the placenta--a review. Fetal Pediatr Pathol. 2010;29 (4): 199-206.

7. Jaffe R, Siegal A, Rat L et-al. Placental chorioangiomatosis--a high risk pregnancy. Postgrad Med J. 1985; 61 (715): 453-5.

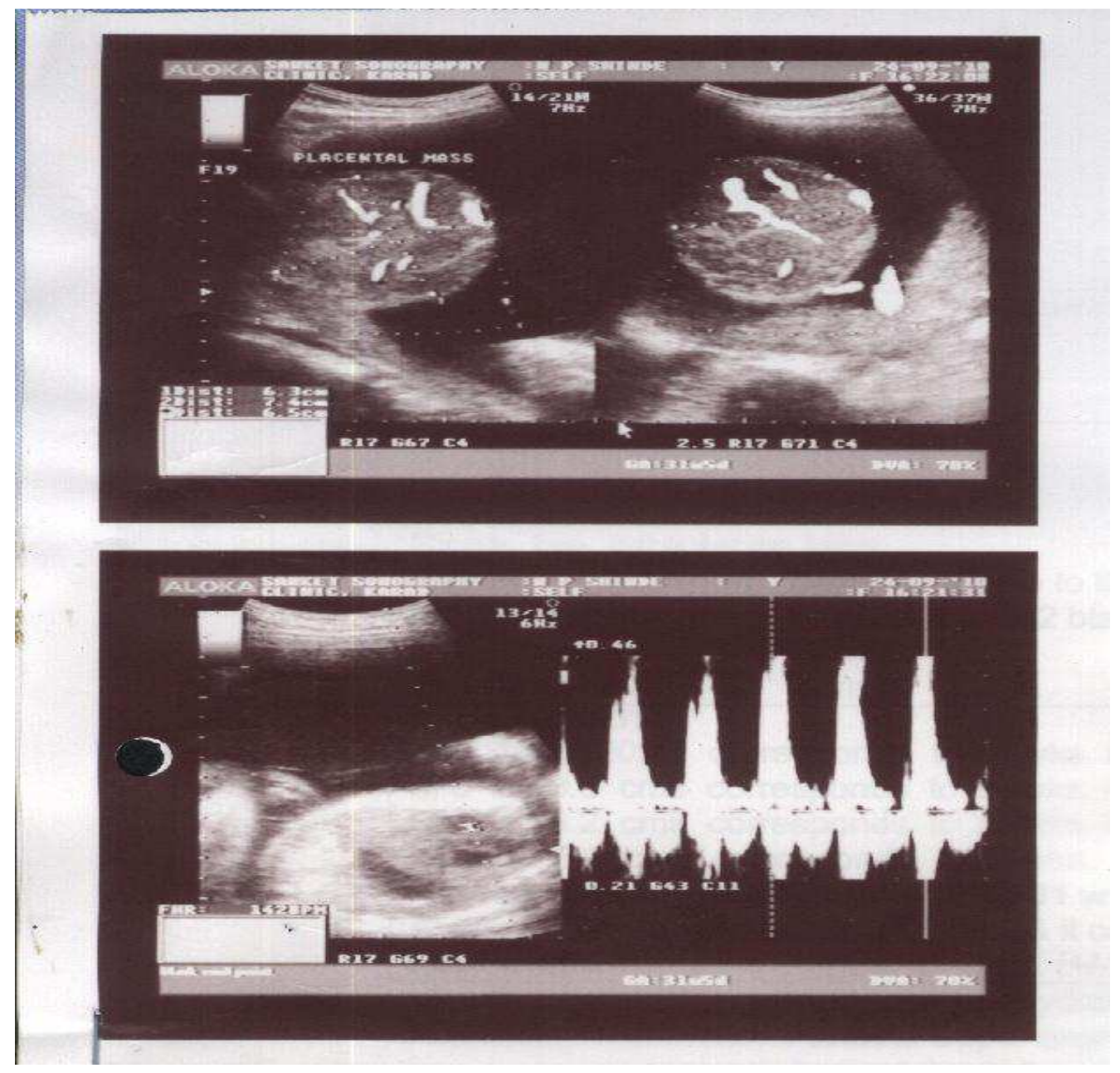



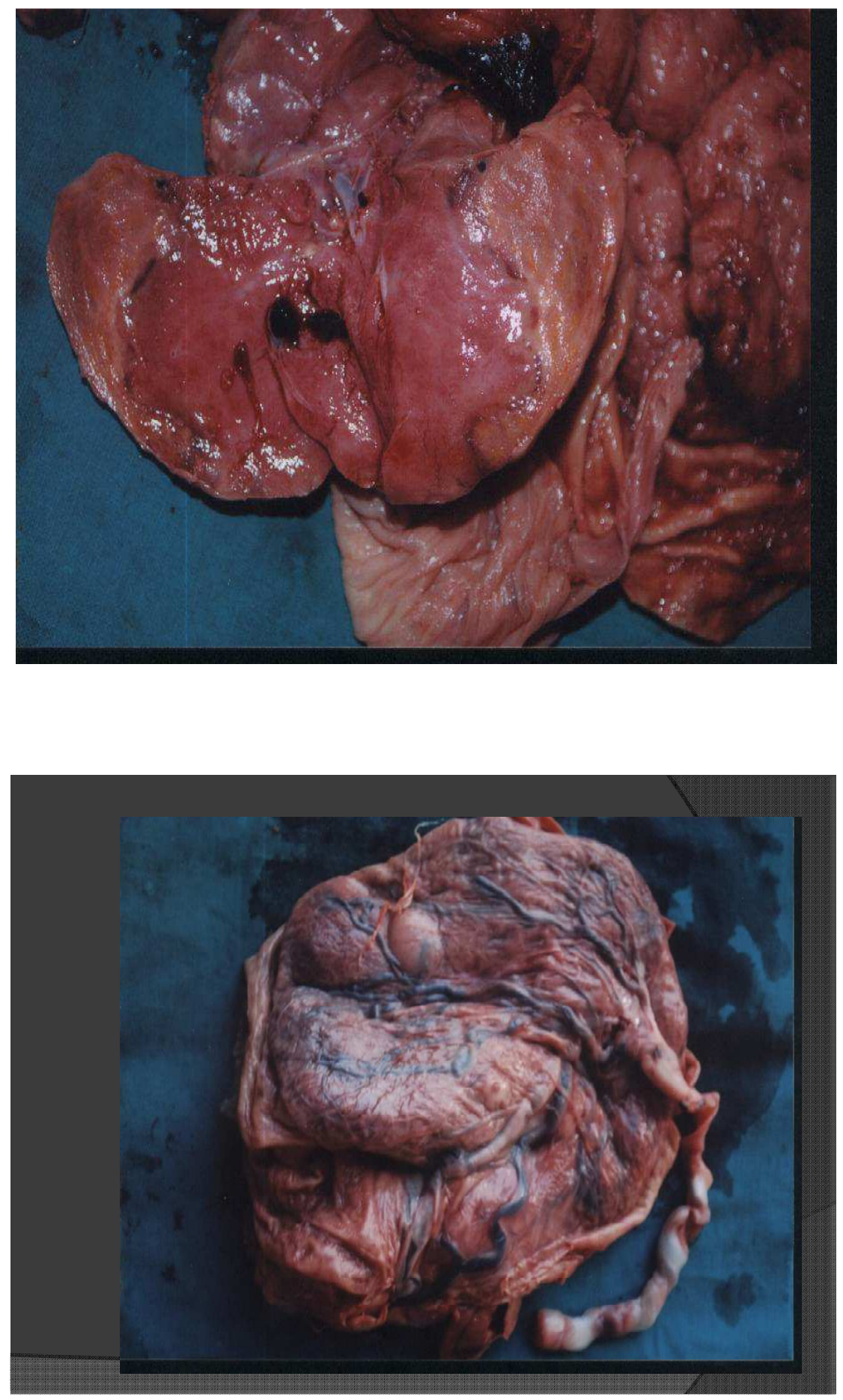


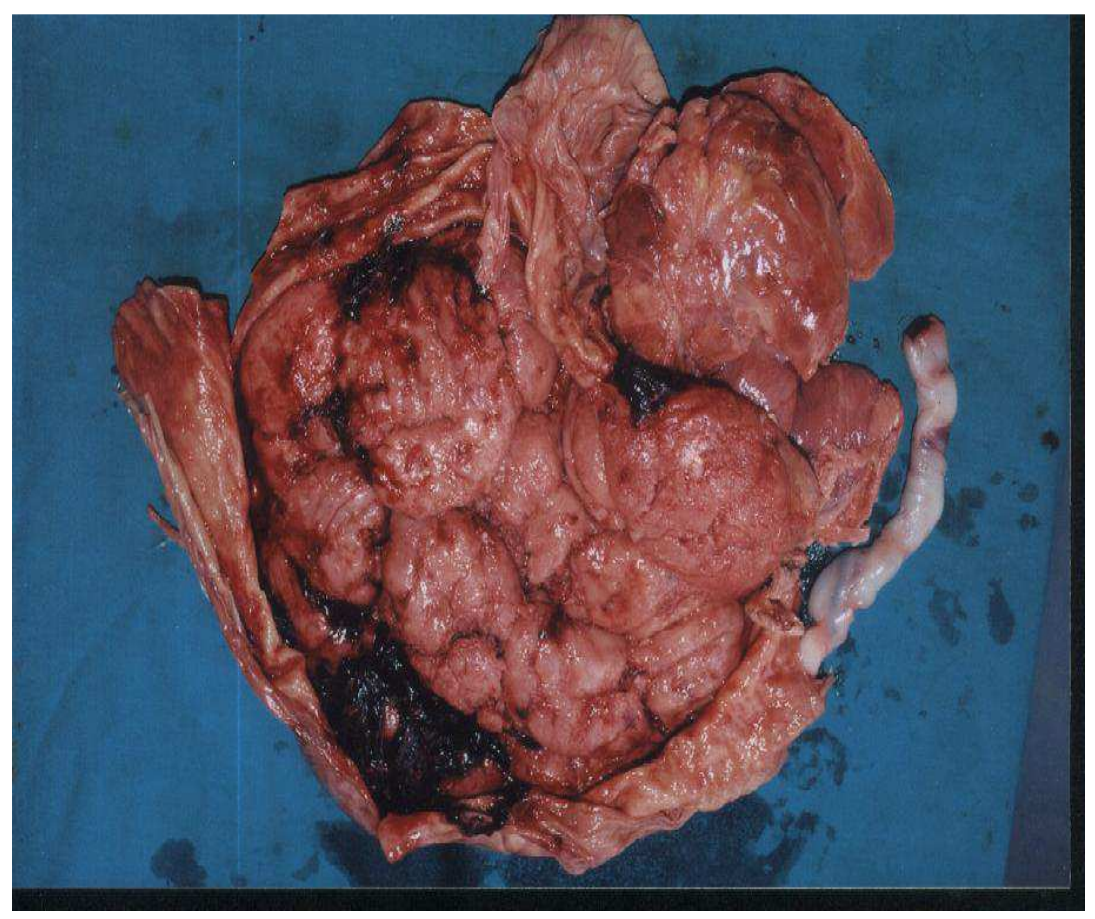

Microscopy- Sections through masses showed proliferation of vascular channels of varying sizes predominantly small capillaries. Sections through placenta showed tertiary villi \& few hypo vascular villi. Sections through cord \& membranes were unremarkable

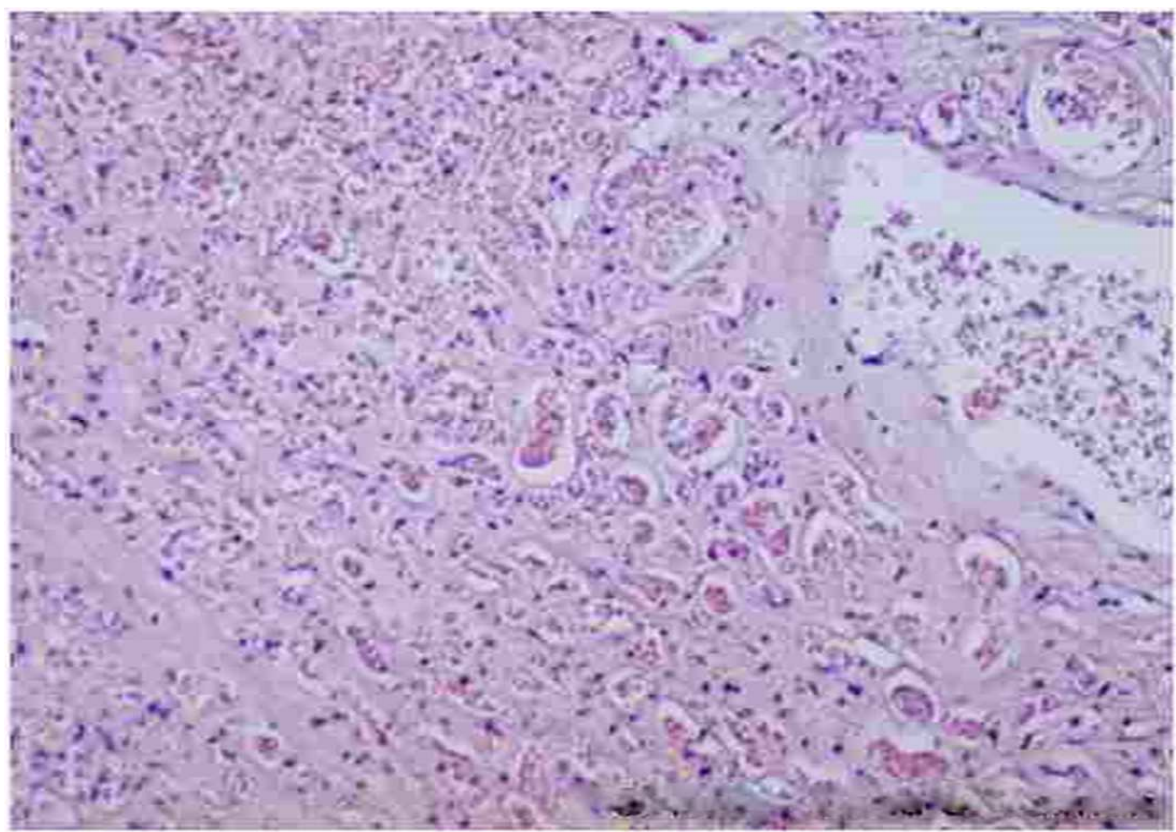

Impression -Multiple hemangiomas/chorioangiomas - placenta 